Full length article

\title{
ASSESSMENT OF TEMPORAL FLOW VARIABILITY OF THE KABUL RIVER
}

\author{
M. Arfan', *, A. H. Makhduml, G. Nabi2 \\ 1. World Wide Fund for Nature-Pakistan \\ 2. Center of Excellence in Water Resource Engineering, University of Engineering and Technology Lahore
}

\begin{abstract}
Water resources estimation under changing flow regimes is required for planning and smooth distribution of water to provinces. Since the hydrological parameters are changing significantly due to climate change, the changes in the pattern of flow regimes are definite. The objective of present study was to assess the spatial and temporal hydro variability of Indus basin. The data of Kabul river at Nowshera before its confluence with Indus river were collected from Surface water Hydrology Project (SWHP), WAPDA. The seasons were divided as three and six month keeping in view the hydrological cycle. Trends and variation were investigated by applying the Mann-Kendall test and Sen's method. The presence of trends tested at different significant level, $99.9 \%, 95 \%$ and $90 \%$. The overall analysis indicates that there is more flow variation on seasonal basis as compared to the annual basis. The Kabul river showed decreasing trend in the maximum mean annual discharge, whereas the minimum mean annual discharge showed increasing trend. It was concluded that Kabul river showed decreasing trend in annual mean and maximum discharge, whereas annual minimum discharge showed increasing trend. It was also noticed that Kabul river mean minimum discharge time series decreased during 1961 1985, whereas it increased during 1986-2010. It was also found that annual mean and maximum discharge decreasing rate was greater during 1986-2010. It was further concluded that each decade experienced one or two years of both dry and wet periods and that 2000-2004 was the driest period in the history of Kabul River.
\end{abstract}

KEYWORDS: Climate change, Indus basin, flow regimes, mann-Kendall

*Corresponding author: (Email: mapiish37@gmail.com, Phone: 0092-346770908)

\section{INTRODUCTION}

The economic life of Pakistan highly hinge on the flow of the Indus river basin which supports large areas of irrigated agriculture and has a substantial role in generating hydro power for the country. More than $80 \%$ of flow in the Indus as it emerges onto the Punjab plains is derived from seasonal and permanent snowfields and glaciers.

The Upper Indus Basin consists of a series of mountain ranges of extreme ruggedness and high elevations. Pakistan's Indus river basin system consist of six major rivers, namely the Indus, Jhelum, Chenab, Kabul, Ravi and Sutlej. These six rivers supply water to the entire
Indus basin irrigation system. These rivers have their origin in the higher altitudes and derive their flows mainly from ice melt and monsoon rains.

The Kabul River is a 700-kilometre (430 mi) long river that materializes in the Sang lakh Range of the Hindu Kush Mountain in Afghanistan and drains into the Indus River near Attock, Pakistan. It is the main river in eastern Afghanistan and it is separated from the watershed of the Helmand by the Unai Pass. The Kabul River passes through the cities of Kabul and Jalalabad in Afghanistan before flowing into Khyber Pakhtunkhawa in Pakistan some 25 kilometers (16 miles) north of the Durand Line border crossing at Torkham. The 
major tributaries of the Kabul River are the Logar, Panjshir, Kunar, Alingar, Bara and Swat rivers. The Kabul River is little more than a trickle for most of the year, but surges in summer due to melting snows in the Hindu Kush Range. Its largest tributary is the Kunar River, which starts out as the Mastuj River, flowing from the Chiantar glacier in Chitral, Pakistan and after flowing south into Afghanistan it is met by the Bashgal river flowing from Nurestan. The Kunar meets the Kabul near Jalalabad. In spite of the Kunar carrying more water than the Kabul, the river continues as the Kabul River after this confluence, mainly for the political and historical worth of the name. The Kabul River is impounded by several dams. The Naghlu, Surobi and Darunta dams are located in Kabul and Nangarhar provinces of Afghanistan. The Warsak Dam is in Pakistan, approximately 20 $\mathrm{km}$ northwest of the city of Peshawar. The climatic changes impact on different hydrological parameters like precipitation. These climatic changes result in the form of severe hydrological changes in river flows. For proper water management and planning, we need appropriate and deep understanding of these changes. These spatial and temporal changes in the flows of Indus basin tributaries impact on the Indus basin irrigation system (IBIS). Some studies are available concerning climate and hydrology in Indus basin. Archer and Flower [1] studied the hydrological variability in the upper Indus basin and their implications on the water resources. In this study they investigated the flow data from 1961 to 1999 and established different correlations/ linkages between the climatic and hydrological variables. They found out that there were significant increase in winter, summer and annual precipitation and significant warming occurred in winter whilst summer showed a cooling trend. Also linkages have been established between seasonal precipitation, temperature and runoff. Time series analysis of those data showed regional trend in precipitation and temperature since 1961. It was noted that precipitation and winter temperature move upward and summer temperature goes down significantly. The study concludes that runoff from foothill and snow fed catchment may be significantly affected, whereas there may be little impact on runoff on glacier fed catchment. Asim et al. [2] analyzed the surface water resources and water delivery system in the Indus basin. The mean annual river runoff in the system was found around 172 BCM. This study throws light on the important issues relating to the management of surface water resources in the Indus basin. Pakistan water resources system has the capacity to cope the scarcities of river flow from 10-13\% but if the system river inflows drop from 15-20\% water shortages occur in respect of irrigation supplies. Archer and Flower $[3,4]$ studied the spatial and temporal variation in precipitation in the upper Indus basin, global teleconnections and hydrological implications. In that study spatial variation in precipitation has been investigated by correlation and regression analysis of long period records. That study found out positive correlation between winter precipitations at stations over the entire region, where as spatial correlation in seasonal precipitation were weaker in summer and sometimes significant between station north and south of the Himalayan divide. Preliminary analysis has identified significant correlation between north Atlantic oscillation and winter precipitation in the karakoram. 
Hydrological regimes are studied by taking stream flow data from nineteen long period stations in terms of annual and seasonal runoff. David Archer [5] studied contrasting hydrological regimes in the upper Indus basin. In this study satisfactory levels of correlation were achieved between stream flow and measurement of temperatures and precipitation at valley sites, which help as a basis for assessing seasonal flow volumes. In this study he also suggested the possibility extending records back on the basis of the historical climatic records. Singh and Sen. Roy et al. [6] evaluated the climatic variability and hydrological extremes in a Himalayan catchment. Monthly and annual analysis of climatic data viz temperature and rainfalls were carried out for Bhuntar and Manali separately. No clear trend was visible for temperature, because some of the months showed increasing trend, whereas some months showed a decreasing trend. For rainfall, annual and monthly values showed wide fluctuation with clear dry and wet periods visible over the years. Annual rainfall trend was mildly increasing, whereas the seasonal rainfall showed a slightly increasing trend in winter, while the monsoon rainfall showed a slightly decreasing trend. Walter [7] studied the hydrological response to climate change in a glacier fed catchment in the Himalayas. He assessed the future development of the glacier and the runoff using an ensemble of downscaled climate models in the Langtang catchment in Nepal. The study showed that both temperature and precipitation are projected to increase; it results into a steady decline of the glacier area. The study also showed that river flow is projected to increase significantly due to increased precipitation and ice melt. In this study we try to assess these spatial and temporal changes in hydrologic availability in different periods of the year through statistical analysis of the historic data of Kabul river station near Nowshera. This study helps in the appropriate water management and planning for different sectors in the country throughout the year. This allows assessment of the impacts of trends or periodic variations in flow of Kabul river basin. This study will help in understanding the erratic flow pattern of Kabul River.

\section{Data and methods}

The temporal analysis of following time scales for discharge was to examine whether flows is certainly changing in the study area.

i. Maximum Discharge Analysis

ii. Minimum Discharge Analysis

iii. Mean Discharge Analysis

The overall period 1961-2010 was subdivided into two 25-year periods, and the complete measurement period. The data of Kabul River sites were collected from surface water Hydrology Project (SWHP), WAPDA for period 1961-2010. Daily maximum, minimum and mean values were used to calculate the monthly maximum, minimum and mean discharge series. Mean annual and seasonal means were calculated for each year. Non-parametric tests are generally distribution-free. They detect trend/change, but do not quantify the size of the trend/change. They are very useful because most hydrologic time series data are not normally distributed. Mann Kendall test [8] is widely adopted to assess significant trends in time series $[8,9]$. It is a nonparametric test, less sensitive to extreme sample values, and independent from the hypothesis about the nature of the trend, either linear or not. To compute the true slope of trend (change per year) Sen's nonparametric procedure was 
used. The Sen's estimator of slope is the median of these $N$ values of discharge (Q). The median of the $N$ slope estimates was obtained in the usual way; $N$ values of $Q$ iare ranked from smallest to largest and compute the Sen's estimator as follow:

$$
\text { Sen's estimator }=Q_{[(N+1) / 2]} \quad \text { (3.6) }
$$

If $N$ was odd and

$$
\frac{1}{2}\left(Q_{N / 2}+Q_{[(N+2) / 2)]}\right)(3.7)
$$

If $N$ was even

Data were processed using an Excel macro named MAKESENS created by Salmi et al. [8].

\subsection{Computation of the Draught and} Flooded Period Indices

There are several indices that measure how much precipitation for a given period of time has deviated from historically established norms.

The most commonly used for agroecological zoning are the followings:

a. Percent of Normal

b. Decile

c. Palmer Drought Severity Index (PDSI)

d. Surface Water Supply Index (SWSI)

Although none of the major indices is inherently superior to the rest in all circumstances, some indices are better suited than others for certain uses.

\subsection{Decile Indices}

The distribution of the time series of the cumulated precipitation for a given period is divided into intervals, each corresponding to $10 \%$ of the total distribution (Decile). Gibbs e Maher (1967) proposed to group the deciles into

\begin{tabular}{|c|c|c|}
\hline Class & Percent & Period \\
\hline \multirow[t]{2}{*}{ Decile 1-2 } & $20 \%$ lower & much below \\
\hline & & normal \\
\hline Decile 3-4 & $20 \%$ following & below normal \\
\hline Decile 5-6 & $20 \%$ medium & near normal \\
\hline Decile 7-8 & $20 \%$ following & above normal \\
\hline Decile 9-10 & $20 \%$ high & much above \\
\hline & & normal \\
\hline
\end{tabular}
classes of events as listed in the following table:

\section{RESULTS AND DISCUSSION}

\subsection{Discharge Trend in Annual Maximum,}

\section{Minimum and Mean Discharge}

Discharge analysis of maximum and mean discharge time series showed decreasing trend for period 1961-2010, whereas minimum discharge time series showed increasing trend. Maximum discharge time series decreased at $99.9 \%$ significance level. In conflicting to the maximum discharge time series, minimum discharge time series increased at $95 \%$ significance level. Mean discharge series showed decreasing trend but not significantly as shown in table 1. In a comparison of 25 year time period, it was concluded that discharge during 1986-2010 decreased more rapidly with respect to 1961-1985 for maximum and mean discharge values, whereas minimum discharge for 1961-1985 was decreased and for 1986-2010 showed increase in discharge as shown in fig. 1, 2 and 3. It was an evidence of the change/ Increase of temperature in the Kabul river catchment which resulted in the higher rate of snow and glacier melting.

\subsection{Discharge Trend in Seasonal (Six Month) Maximum, Minimum and Mean Discharge}

\subsubsection{Discharge trend in winter (O-M) maximum, minimum and mean discharge \\ Discharge trend analysis in minimum, and mean discharge time series showed increase for}


1961-2010, whereas maximum discharge time series showed a decreasing trend. Maximum discharge time series decreased at $90 \%$ significance level. Contrarily to the maximum discharge time series, minimum discharge time series increased at $99.9 \%$ significance level. Mean discharge series showed increasing trend but not significantly, as shown in table 1. In a comparison of 25 year time period, it was concluded that from 1986-2010 maximum and mean discharge showed more decrease as compared to the 1961-1985, whereas minimum discharge was found during 1961-1985. Similarly, a decreasing and reversed pattern was found for 1986-2010 as shown in fig. 1, 2 and 3. It was again an evidence of the change/ Increase of temperature in the Kabul river catchment which resulted in the higher rate of snow and glacier melting.

\subsubsection{Discharge trend in summer (A-S)} maximum, minimum and mean discharge

Analysis of maximum and mean discharge time series, showed decreasing trend for 19612010, whereas minimum discharge time series showed increasing trend. Maximum discharge time series decreased at $99.9 \%$ significance level. Contrarily to the maximum discharge time series minimum discharge series increased at a 90\% significance level. Mean discharge series showed decreasing trend but not significantly as shown in the table 1. The comparison of 25 year time period, revealed a more decreasing trend in 1986-2010 as compared to the period of 1961-1985 in maximum and mean discharge. Minimum discharge decreased during 19611985 as compared to the 1986-2010 decade, which showed increase in discharge as shown in fig. 1, 2 and 3.

\subsection{Discharge Trend in a Seasonal (Three Month) Maximum, Minimum and Mean Discharge}

\subsubsection{Discharge trend in winter (DJF) maximum, minimum and mean discharge}

Analysis of minimum, and mean discharge showed increasing trend for 1961-2010, whereas maximum discharge showed decreasing trend. Maximum discharge decreased at a $95 \%$ significance level. Conversely to the maximum discharge, minimum and mean discharge increased but not significantly as shown in table 1. The comparison of 25 year time increment, indicated a more rapidly decreasing trend during 1986-2010 in discharge with respect to 1961-1985 as shown in fig. 1, 2 and 3.

\subsubsection{Discharge trend in spring (MAM) maximum, minimum and mean discharge}

Analysis of maximum and mean discharge showed decreasing trend for 1961-2010, whereas mean minimum discharge time series showed increasing trend. Maximum discharge time series decreased at a $99 \%$ significance level. Contrary to the maximum discharge, minimum discharge increased at a $99 \%$ significance level. Mean discharge series showed decreasing trend but not significantly as shown in table 1. In a comparison of 25 year time increment, it was concluded that the time interval 1986-2010 has more decreasing discharge with respect to the 1961-1985 period for maximum and mean discharge time series, whereas minimum discharge during 1961-1985 is decreasing and during 1986-2010 increasing as shown in fig. 1, 2 and 3.

\subsubsection{Discharge trend in summer (JJA) maximum, minimum and mean discharge}


Analysis of maximum and mean discharge showed a decreasing trend for the period of 1961-2010, whereas, minimum discharge indicated an increasing pattern. Maximum discharge decreased at $99.9 \%$ and $90 \%$ significance level. Contrarily to the maximum discharge time series, minimum discharge time series increasing but not significantly as shown in the table 1.

Table 1: Trends in Annual Max., Min. and Mean Discharge of Kabul River for the period (1961-2010) and 25 year time interval showing Discharge change in 1000 Cusec decade $^{-1}$

\begin{tabular}{|c|c|c|c|c|c|c|c|c|c|}
\hline \multicolumn{10}{|c|}{ Discharge Change per Decade (1000Cusec) } \\
\hline & \multicolumn{3}{|c|}{ Mean Max. Discharge } & \multicolumn{3}{|c|}{ Mean Min. Discharge } & \multicolumn{3}{|c|}{ Mean Annual Discharge } \\
\hline Seasons & 1961-2010 & |1961-1985 & $1986-2010$ & 1961-2010 & |1961-1985 & |1986-2010 & 1961-2010 & 1961-1985 & 1986-2010 \\
\hline $\begin{array}{l}\text { Annual (J- } \\
\text { D) }\end{array}$ & $0.45^{8 * * 3}$ & $\cdot 0.498+$ & $\cdot 1.089 *$ & $0.128^{*}$ & $-0.150+$ & $0.345^{5}$ & -0.088 & $.0 .327^{*}$ & -0.129 \\
\hline \begin{tabular}{|l} 
Winter(0. \\
M)
\end{tabular} & $\cdot 0.107+$ & -0.078 & $.0 .512^{*}$ & $0.064^{* * *}$ & -0.031 & $0.119^{*}$ & 0.029 & -0.051 & -0.039 \\
\hline $\begin{array}{l}\text { Summer } \\
\text { (A-S) }\end{array}$ & $\cdot 0.877^{4 * 8}$ & $-1.034+$ & $\cdot 1.459^{*}$ & $0.195+$ & $.0 .254^{4}$ & $0.556^{*}$ & -0.18 & $.0 .586^{\circ}$ & -0.172 \\
\hline \begin{tabular}{|l} 
Winter (D. \\
F)
\end{tabular} & $\cdot 0.065^{5}$ & -0.07 & $.0 .248^{*}$ & 0.009 & $-0.065^{5 x}$ & -0.017 & 0.017 & -0.05 & 0.006 \\
\hline \begin{tabular}{|l|} 
Spring(M- \\
M)
\end{tabular} & $-0.721^{* *}$ & $-1.065+$ & $-1.406^{*}$ & $0.192 * *$ & -0.224 & $0.381+$ & -0.033 & -0.242 & -0.294 \\
\hline $\begin{array}{l}\text { Summer } \\
\text { (J-A) }\end{array}$ & $\cdot 0.945^{* * 8}$ & -0.902 & $\cdot 1.990^{*}$ & 0.192 & -0.34 & 0.67 & $-0.333+$ & $\cdot 0.925^{*}$ & -0.247 \\
\hline \begin{tabular}{|l} 
Autum(s. \\
N)
\end{tabular} & $\cdot 0.193^{* *}$ & -0.028 & $\cdot 0.513^{*}$ & $0.082^{* * *}$ & -0.072 & $0.152^{* *}$ & -0.026 & -0.039 & -0.083 \\
\hline
\end{tabular}

***Significance level <=99.9\%, **Significance level <= $99 \%$. ${ }^{*}$ Significance level $<=95 \%$. +Significance level $<=$ $90 \%$. Bold $=$ Negative Significant Trend

In a comparison of 25 year time increment it was concluded that the time interval 1986-2010 displayed a more decrease in maximum discharge with respect to the 1961-1985 period and reverse for mean discharge. Minimum discharge during 1961-1985 was found decreasing and increasing during 1986-2010 as shown in fig. 1, 2 and 3. It was an evidence of the change/ increase of temperature in the Kabul river catchment, which resulted in the higher rate of snow and glacier melt.

\subsubsection{Discharge trend in autumn (SON)} maximum, minimum and mean discharge

Analysis of maximum and mean discharge showed decreasing trend for period 1961-2010, whereas, mean minimum discharge showed increasing trend. Maximum discharge decreased at $99 \%$ significance level, whereas, minimum discharge increased at a $99.9 \%$ significance level. Mean discharge series showed decreasing trend but not significantly as shown in Table 1. In a comparison of 25 year time increment, the time interval 1986-2010 shows more decreasing in maximum and mean discharge with respect to 1961-1985, whereas minimum discharge decrease during 1961-1985 and 1986-2010 showed increasing discharge, as shown in figure 1, 2 and 3.

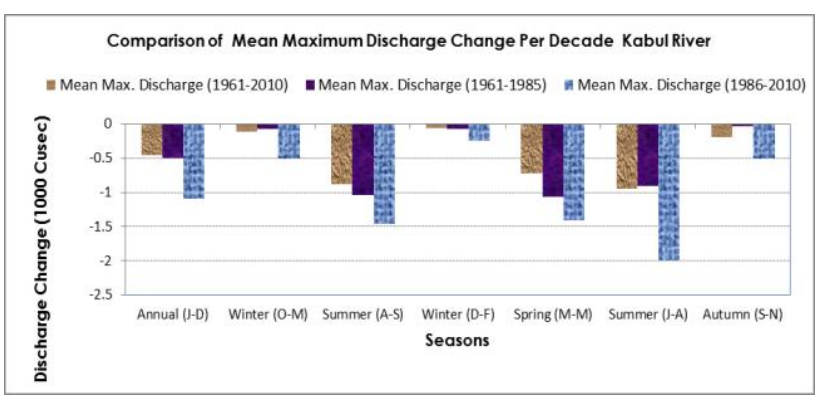

Figure 1. Comparison of Mean Maximum Discharge

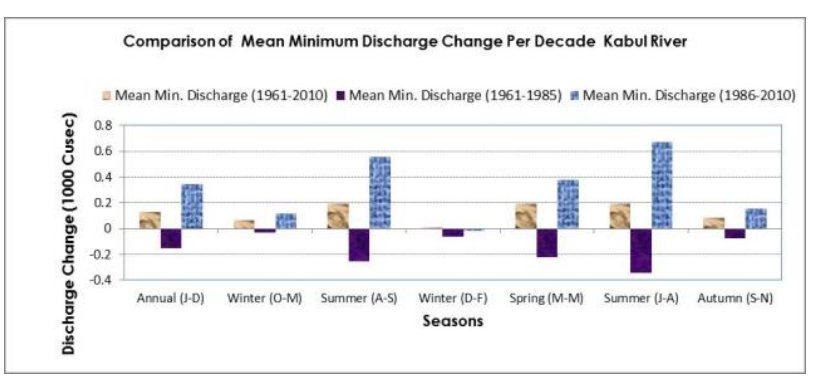

Figure 2. Comparison of Mean Minimum Discharge 


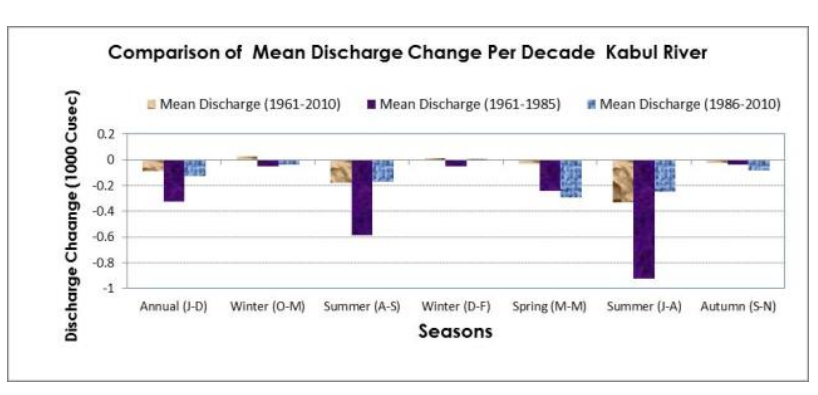

Figure 3. Comparison of Mean Discharge

\subsection{Drought and Flooded Period Analysis}

Drought and flooded period analysis proceeds by using the Decile indices technique. Decile technique first arranges the data separately in ascending order and then divides them into $20 \%$ Decile and made 10 categories. Decile 1-2 shows the drought period in the data; this means values laid in this Decile range are much below the mean and Decile 9-10 shows flooded period in the data, i.e. values laid in this Decile range are much above the mean value. Figure 4 shows the years experience drought and flooded period in the Kabul river. It shows that every decade must experience drought as well as flood but there is no clear cut cyclic pattern. To investigate the cyclic pattern in the discharge, there is a need to investigate a long term discharge analysis series.

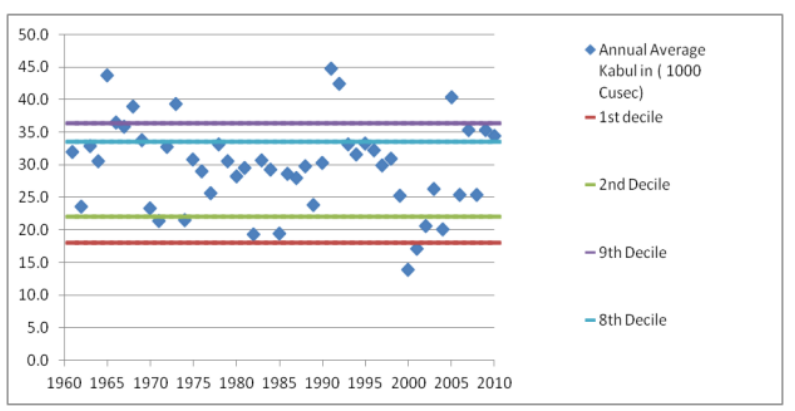

Figure 4. Comparison of Draought and Flooded period.

\section{CONCLUSIONS AND RECOMMENDATIONS}

1. It was concluded that there is more and significant flow variation on seasonal basis as compared to the annual basis.

2. The minimum discharge of Kabul river increases significantly lately 1986-2010, being an evidence of minimum temperature rise and land use, land cover changes of the catchment.

3. Kabul river annual flow comprises of $82 \%$ share of summer flow and seasonal analysis of summer (A-S) and Summer (JJA) showed decreasing discharge lately possibly due to continuously negative mass balance of glacier and ice melts in the catchment area of Kabul river .

4. It was concluded that Kabul river showed decreasing trend in annual mean and maximum discharge, whereas annual mean minimum discharge showed increasing trend.

5. It was also noticed that Kabul river minimum discharge decreased during 1961-1985, whereas, it increased during 1986-2010.

6. It was also found that annual mean and maximum discharge decreasing rate is larger during 1986-2010.

Following are the recommendations:

1. Some hydrologic simulation models should be used to see contemporary impact.

2. Co-relation of temperature and precipitation parameters with the flow gives more insights into the hydrological phenomenon of the basin.

\section{References}

[1] H.J. Fowler, D. R. Archer, Hydroclimatological variability in the Upper Indus Basin and implications for water resources. Regional Hydrological Impacts of Climatic Change-Impact Assessment and Decision 
Making, IAHS Publication, Rev. E. 295 (2005) 131-138.

[2] A.R. Khan, Analysis of hydrometeorological time series: Searching evidence for climatic change in the Upper Indus Basin. Lahore, Pakistan: International Water Management Institute. (IWMI working paper 23).

[3] D.R. Archer, Hydrological implications of spatial and altitudinal variation in temperature in the Upper Indus Basin, Nordic Hydrology, Rev. E. 35 (2004) 209222.

[4] D.R. Archer, H.J. Fowler, H .J, Spatial and temporal variations in precipitation in the upper Indus Basin, global teleconnections and hydrological implications. Hydrology and Earth System Science Rev. E. 8 (2004) 47-61.

[5] D.R. Archer, Contrasting hydrological regimes in the upper Indus Basin, Hydrology. Rev. E. 274(2003) 198-210. 5

[6] D.R. Archer, N. Forsythe, H.J. Fowler, S.M. Shah, Sustainability of water resources management in the Indus Basin under changing climatic and socio economic conditions, Hydrology and Earth System Science Rev. E. 7 (2010) 1883-1912. 6

[7] W. Walter, Immerzed, L.P.H Van Beek, M.Konz, A.B. Shreshta, M.F.P. Bierkens, Hydrological response to climate change in a glacierized catchment in the himalays, Climate Change, Rev. E. 110 (2011) 721 736.C.T. Haan, Statistical Methods in Hydrology, The lowa State Univ. Press, Ames, (1997).

[8] M.G. Kendall, Rank correlation methods, 4th ed. Charles Griffin, London, (1975). 9

[9] M. Akhtar, N. Ahmad, M.J. Booij, The impact of climate change on the water resources of Hindukush-KarakorumHimalaya region under different glacier coverage scenarios ,Hydrology. Rev. E 355(2008) 148-163. 